\title{
Spanish influenza: analogue for potential ramifications of bioterrorism
}

\author{
K. Duncan \\ Health Studies, University of Toronto at Scarborough, Canada
}

\begin{abstract}
During the $20^{\text {th }}$ century, influenza threatened the world in $1918-19,1957-58$, and 1968-69; the latter two pandemics killed a total of three million people. In stark contrast, the Spanish influenza of 1918 killed an estimated 50 million peopleeven though eighty percent of patients suffered only the usual three- to five-day illness. Twenty percent of all influenza patients developed pneumonia, and half of those died.

In North America, the Spanish influenza pandemic serves as a useful analogue for the potential ramifications of a major epidemic caused by one of the serious biological weapons, such as Variola major (smallpox), Bacillus anthracis (anthrax), Yersinia pestis (plague), Botulinum toxin (produced by Clostridium botulinum), and a number of the causative agents of the syndrome termed viral haemorrhagic fever.

Although case fatality rates were 1.9-5.0 percent for Spanish influenza, they might reach 30-80 percent for untreated smallpox and anthrax. In Canada, the 1918 influenza pandemic caused 50,000 deaths, widespread social disruption, and enormous burdens on healthcare and civil infrastructure. A catastrophic epidemic resulting from bioterrorism would 'severely tax society's ability to care for the sick and dying, and to contain disease.'

Preparations for a bioterrorist attack must therefore include several capabilities - to characterize any outbreak, to allocate health resources fairly, to care for mass casualties, to provide mass burials that respect social codes, and to address psychological impacts.

In light of the foregoing, this paper utilizes the 1918 Spanish influenza in Toronto, Canada, as an analogue for the possible impacts of a bioterrorist attack, and makes recommendations for preparedness, safety, and security.
\end{abstract}

Keywords: Spanish influenza, bioterrorism, preparedness, safety, security. 


\section{Spanish influenza: spring and summer 1918}

Spanish influenza had largely gone unnoticed in the spring and summer of 1918 . In fact, the spring wave of the disease was not even mentioned in the index of the 1918 volume of the Journal of the American Medical Association (Beveridge [1]) perhaps because the disease had been mild, the mortality was not unusually high, and the world had had enough with which to contend - the fifth year of war (Beveridge [1]; and Pettigrew [2]). However, influenza was quietly brewing, with localized outbreaks among military camps in the United States in the early months of 1918. On March 11th, 107 American servicemen became ill in only one day at Camp Funston, Fort Riley, Kansas. By the end of the five-week training camp, 1127 men had been stricken, and 46 had died of pneumonia following the flu (Pettigrew [2]). Camps Doniphan, Fremont, Gordon, Grant, Hancock, Lewis, Logan, Kearney, McClellan, Oglethorpe, and others also reported epidemics in March and April (Duncan [3]).

By April the disease had spread to France - perhaps carried there by American troops (Beveridge [1]). And by the end of April, influenza had reached Spain, where the disease was widely publicized. Neutral Spain had no censorship of its press, unlike countries at war. Spain made the first public announcement of the disease. Madrid cabled London: 'A strange form of disease of epidemic character has appeared in Madrid (Beveridge [1]; Pettigrew [2]; and Duncan [3]).'

By May the disease had spread to Greece, Macedonia, Egypt, and Britain. In England, 10,313 sailors of the British Navy developed flu and were unable to leave port. And it was in Britain that the Royal College of Physicians labelled the disease 'Spanish influenza' (Crosby [4]).

The unfortunate name stuck, despite the disease's having been given a multitude of names. In Britain the disease had been called 'Flanders Grippe'. In Spain it had been 'Naples soldier'. In Germany, 'Blitz Katarrh' or lightning cold. In Poland it was the 'Bolshevik Disease', and in Ceylon it was 'Bombay Fever'.

Perhaps the name 'Spanish flu' persisted because neutral Spain was unpopular with both warring sides, which were attacked equally by the new foe-'a foe that cut down troops and sent them behind the lines to first aid stations and hospitals (Pettigrew [2]).'

Throughout the spring, there had also been outbreaks on the other side of the world. Influenza had been reported in China, and in the Japanese Navy in March. By May the disease was widespread in Asia (Collier [5]). Most of the deaths were among the elderly, but there were, surprisingly, an appreciable number of deaths among the 20-40-year age group (Crosby [4]).

\subsection{Lessons for bioterrorism response}

A lack of reporting systems seriously hindered public health's ability to first recognize the spread of influenza in the spring of 1918, and later manage autumn's lethal outbreaks (Schoch-Spana [6]; and Duncan [3]). And today, the lack of historical influenza data makes it challenging to determine whether there 
was a 'seeding' of the virus in the years prior to 1918, as has been suggested by Oxford et al., [7]. Mortality figures for bronchopneumonia show an increase in the United States for the period, 1914-1918; and outbreaks of 'purulent bronchitis' occurred in France in 1916 and in Britain in 1917. Accurate influenza statistics in the years prior to the Spanish flu pandemic could perhaps shed light on the possible relevance of today's spread of influenza A H5N1.

A review of history's deadliest disease serves as an excellent case study for policy makers and healthcare professionals engaged in developing suitable public health responses to bioterrorism (Schoch-Spana [6]; and Duncan [3]). Four diseases, namely anthrax, botulism, plague, and smallpox, have recognized bioterrorism potential. Other possible bioterrorism agents include those that cause brucellosis, Q fever, tularemia, viral encephalitis, and viral hemorrhagic fevers.

A first response to a catastrophic epidemic must require the abilities to accurately identify an outbreak, and monitor cases, deaths, and success of epidemic controls (Schoch-Spana [6]). If a bioterrorism event is suspected, local emergency response systems should be activated, with prompt communication with provincial and federal emergency services (APIC et al., [8]).

\section{Spanish influenza: autumn 1918}

In the autumn of 1918, the Spanish influenza virus probably mutated and a worldwide epidemic, or pandemic, of unprecedented virulence exploded in the same week in three port cities, thousands of miles apart: Freetown, Sierra Leone; Brest, France; and Boston, United States of America.

The three epidemics heralded the start of the autumn wave of Spanish flu and the most devastating (in terms of total mortality) disease outbreak in recorded history.

In September, the disease swept Europe, and returning troops carried flu home. In North America, servicemen disembarked from crowded ships at Atlantic ports only to board trains that would take them, along with flu, inland to cities, villages and farms from Newfoundland to California (Schoch-Spana [6]; and Duncan [3]).

Despite the devastation among the world's peoples, most patients developed only a mild flu. Even in the severe autumn wave, 80 percent of patients suffered the usual three- to five-day illness. Patients initially had cough and stuffy nose; later, however, a dreadful ache pervaded every joint and muscle - leaving the patient feeling as if he or she 'had been beaten all over with a club'. If the illness progressed no further, the victim was usually 'back to normal' within one week.

Approximately 20 percent of all influenza patients developed pneumonia; half of those died. The pneumonia often developed rapidly, with some patients experiencing a 'heliotrope colouration of the lips and face'. Men literally choked to death with pulmonary oedema, the lungs so swamped with blood, foam and mucous that the faces were grey and the lips purple.

Doctors and scientists from around the world reported a wide range of symptoms, including kidney complaints, nasal hemorrhage, and even 'silent 
lungs'; Spanish flu seemed to affect so many organs of the body usually untouched by influenza that Dr. Charles Sundell of Britain's Medical Research Council recorded, 'No part of the body is exempt.'

In 1918, the medical profession did not know what caused the disease. Medical practitioners talked of airborne Pfeiffer's bacillus, Pneumococcus, Streptococcus, Staphylococcus, malnourishment, and the crowding together of the world's peoples under conditions of great misery - conditions ideal for the start of an outbreak of infection (Duncan [3]).

\subsection{Lesson for bioterrorism}

In 1918, public health could not isolate the cause of Spanish flu, and as a result, diagnosis was based on clinical manifestations. (Duncan [3]).

Response to a possible bioterrorism event will require prompt identification of the causal agent. However, because of the possibility of swift progression to illness and the potential for dissemination, it may not be practical to await diagnostic laboratory confirmation. Diagnosis may need to be based, as in 1918, on a high-risk syndrome or a typical combination of symptoms (APIC et al., [8]).

\section{Build capacity to provide equitable medical care}

\subsection{Medical personnel and volunteers}

In 1918, practitioners were in short supply and overworked, as the war had already siphoned off thousands - 40,000 of 140,000 American doctors had enlisted (Collier [5]). Moreover, frontline health workers were the first to succumb to influenza. The Toronto Daily Star reported on October $23^{\text {rd }}$ that 54 of the 319 Toronto public health staff members were sick with flu. On October $26^{\text {th }}$, Dr. Swenerton, a prominent surgeon, succumbed while waiting on patients; he was 31 years old. By the end of October, 814 patients were hospitalized in Toronto, including 157 nurses.

As a result, the Toronto Daily Star included a request to Toronto citizens to refrain:

'as much as possible from telephoning to ask regarding the conditions of relatives and friends. With decreased staffs, time can ill be afforded to answer numerous telephone calls...Early in each day a census is taken and when patients are in a critical condition the relatives are advised. When no such notification is received, interested persons may take it for granted that there is no immediate danger.'

As doctors and nurses sickened and died, urgent appeals rang out for additional healthcare workers, volunteers, and help from the public:

'Emergency Appeal!

Voluntary Workers as Nurses Aides required at once.

Also, Ward Maids, Orderlies, Cooks, Cleaners, etc. to help care for victims of influenza. 
Apply today at Ontario Government Bureau.'

Hundreds of women responded to Toronto's call for Volunteer Sisters of Service. The women received three hours of training, and a blue and white satin SOS badge, before heading out into the neighborhoods. In addition, army cadets helped the sick in their homes, while church groups set up soup kitchens, and guides, scouts, and university students were also urged to help the sick.

\subsection{Lessons for bioterrorism}

Extrapolating from 1918, healthcare workers need to be protected. They must be educated and drilled regarding the possibility of a bioterrorist attack, and must be protected from secondary infection. Home care will be necessary, as a contagious disease requires isolation, and hospitals could become overburdened (Schoch-Spana [6]).

It is imperative to determine the number of available healthcare workers, to triage, to determine patient flows, to develop discharge instructions, and to identify suitable organizations to train volunteers for healthcare roles (Duncan [9]).

Each community must be prepared. This includes: developing demographic profiles for communities, including special needs populations and language minorities; developing containment measures (e.g. cancelling public transportation, closing schools and other public venues); and maintaining a current register of all active and once-active healthcare personnel available for emergency services (APIC et al., [8]).

\subsection{Facilities and equipment}

As thousands of people died, more and more buildings were pressed into use as hospitals. Gymnasiums, chapels, and canteens were all commandeered as temporary hotels for the sick and dying. In Queensland, Australia, the church hall served as the hospital. In Montego Bay, Jamaica, the hospital was the 'Northern News', and in Enderline, Nebraska, a run-down railway hotel served as the hospital. In St. John's, Arizona, the hotel for the sick was the abandoned county jail. Nor was it the only jail to serve; the world-famous Sing Sing Prison, 25 miles up the Hudson River from New York City, also did time as a hospital (Collier [5]; and Duncan [3]).

\subsubsection{Lessons}

Today all hospitals should be prepared to meet the surge in demand for healthcare during a bioterrorist attack. Hospitals should also participate in regional planning for the medical care of patients, since hospitals, individually and jointly, must be able to provide care for victims, while maintaining other essential medical services, during and after a catastrophic event. In addition, every hospital should stockpile, or assure access to a stockpile of, personal protective equipment for a sustained time period (APIC et al., [8]; and Duncan [9]). Hospitals should also plan for the re-allocation of scarce equipment, such as respirators. Patients affected by botulinum toxin are at risk of respiratory 
dysfunction that may require mechanical ventilation for two to three months before unassisted breathing is possible. In the event of a large-scale event, hospitals should also plan for their ability to manage a sudden increase in cadavers (Schoch-Spana [6]).

\subsection{Medical supplies}

\subsubsection{Therapies}

In 1918, Dr. Robert Parry of The Middlesex Hospital in London complained that doctors did little more than direct traffic; physicians simply guided people to the emergency wards or to the mortuary. When there was a possibility of helping, doctors without therapeutic drugs could suggest only their time-honoured cures of rest, liquids, and a great deal of hope to cure very ill patients.

Goose-grease poultices, bran poultices, lard and turpentine poultices and compresses of fir-tree spills, mutton tallow and mustard were among the concoctions applied to the chests of the sick. Drinks of warm milk, ginger, sugar, pepper and soda were given to soothe the ill, and cough elixirs were administered to strengthen, heal, and make the flu-stricken well.

One wholesale drug company that normally sold 6000 bottles of cough medicine per week faced a demand of 3000 bottles per day (Duncan [3]).

The Toronto Daily Star reported:

'Drug Stores Sold Out of Influenza Cures

Cough Medicines, Aspirin, Etc. are Being Bought Up Rapidly

Demand Is Terrific

Druggists are Weary of Making Up Prescriptions to Stem Epidemic

Six thousand bottles of cough syrup per week.'

3.4.1.1 Lessons Today, institutions should identify sources to supply antibiotics, immune globulin, botulinum anti-toxin, and vaccines.

In October 2005, the Canadian national antiviral stockpile in preparation for a pandemic influenza was comprised of 16 million doses of oseltamivir (Tamiflu), although some provinces and territories might have purchased additional stores. The supply fell far short of one dose for each Canadian, and in May 2006, the Canadian government announced that 55 million doses would be available for the population (Duncan [9]).

In a bioterrorist scenario, leaders must protect against discrimination and assure equitable allocation of scarce resources-from antiviral drugs to respirators to vaccines (APIC et al., [8]).

In the case of a disease outbreak, for which there are no curative or preventive therapies, compassionate supportive care is essential (Schoch-Spana [6]).

\subsection{Preventive measures}

\subsubsection{Vaccines}

In 1918, desperate people tried totally useless, and in many cases dangerous, vaccines. Some physicians recommended one of the many available vaccinations 
against Spanish flu on the market; all vaccinations had their advocates, all had their detractors, and all were useless.

In Toronto, the Connaught Laboratories, University of Toronto announced:

'Immediately after the outbreak of the epidemic in Toronto, work was commenced on the subject of influenza and this work has been actively carried on with the co-operation of both the military and civil authorities... a vaccine had been prepared in large enough quantities for distribution. The vaccine consists of dead germs of influenza, and eighteen strains of these germs are used in the preparation of the vaccine. These strains were obtained through the New York and Boston authorities and represent strains isolated in these cities, and in several of the army camps in the United States....Yesterday, distribution of the first supply of vaccine was commenced, to the hospitals in Ontario, for the use of the nurses and doctors, and to the army authorities. The first supply of vaccine amounted to 7,000 doses... The University desires to point out that as the vaccine is extremely difficult to prepare, it should be used first, in those places where it is most needed. The vaccine will be distributed by the University entirely free at the present.'

One wonders what 'strains' were used in the preparation, as the first human influenza virus was not isolated until fifteen years later at the National Institute for Medical Research (NIMR) at Mill Hill in London, England (Duncan [3]). Moreover the Toronto Daily Star reported that 'The Spanish influenza germs are of a vegetable nature.'

Regardless, the paper reported that the vaccine was popular, with ' 52 pints having been distributed by the Provincial Health Dept. throughout Ontario.' It was further reported that, 'We have endeavoured to distribute it as fairly as possible. We have supplied it to the medical officers of health, to hospitals, and to the troops. It is too early to know what results have been achieved by it use.'

3.5.1.1 Lessons Nevertheless, the above information highlights a key public health issue for today - namely, the desperation for protective measures and their fair distribution.

Vaccines may have limited availability (e.g. anthrax) or may not be available (e.g. pneumonic plague) or recommended (e.g. botulism) for the general population.

Therefore, other protective measures would include infection control measures related to patient management: gloves, hand-washing, isolation, protective equipment (e.g. eye protection, face shield, gown), and sterilization of environment and equipment. Agent-specific recommendations should be followed (APIC et al., [8]).

\section{Post-mortem care}

In 1918, upwards of 50 million people succumbed to Spanish flu in a global population of two billion people - and this is a conservative estimate, as it is believed that 25 million may have died in India alone. Many researchers now 
estimate the number of dead at 100 million. Spanish flu killed more people than the Black Death of the Middle Ages, more people than all the fighting of the First World War, more people than AIDS has to date, and, remarkably, Spanish flu killed in a period of just one year.

Spanish flu killed an estimated 550,000 people in the United States of America. The disease killed 19,000 in New York City alone. In Philadelphia, 521 people died in one day, and at the height of the crisis, 4500 died in just one week. The Philadelphia morgue was built for only 36 corpses; as a result, several hundred bodies were piled three and four deep. Every room and corridor was packed with the dead - covered with dirty, blood-stained sheets. Before flu disappeared, Philadelphia was forced to open five supplementary morgues to hold the victims (Crosby [4]; and Beveridge [1]).

In Canada, 50,000 died. Fourteen thousand of the Canadian flu victims perished in the Province of Quebec. In Montreal, Quebec, the demand for transporting coffins was so great that trolley cars had to be converted to hearses. A trolley car could carry ten coffins at a time (Pettigrew [2]).

In Hamilton, Ontario, eight cabinet makers worked around the clock to keep up with the demand for coffins. Undertakers would take one casket to the cemetery, and would hurry back to the church to pick up the next.

In Toronto, Ontario, funerals were allowed on Sunday; and white hearses for children became a common sight. So too were sashes on doorways: a white sash for a child; a grey one for a middle-aged person; and a purple sash for a senior citizen (Pettigrew [2]; and Duncan [3]).

Elsewhere in the world, coffins and undertakers were in equally short supply. Those who were fortunate buried their dead in plain, unvarnished boxes, often fashioned from doors and floorboards. In many countries, however, the dead were interred in cardboard boxes, blankets, or paper shrouds, and piled in mass graves.

In Rio de Janeiro, one householder pleaded with the fire brigade, conscripted as undertakers, to remove his dead brother. They refused, adamant that there was no room on the death cart. However, the desperate brother continued to plead, as the corpse was five days old. The firemen relented; they would take the brother, but, in return, they would leave a stranger who had died more recently (Beveridge [1]; and Duncan [3]).

\subsection{Lessons}

Regardless of the numbers of dead, protocols must be developed to prepare for excess mortality and to handle bodies in a safe and respectful manner (Duncan [9]).

Pathology departments and laboratories should be warned regarding the possibility of an infectious disease outbreak before any specimens are submitted for screening or disposal. All autopsies should be performed using personal protective equipment, including masks and eye protection (APIC et al., [8]; and Schoch-Spana [6]). 


\section{Psychological impacts}

Spanish flu killed young healthy people, adults, 20-40 years of age. For example, Spanish flu killed Harry Elionsky, America's strongest swimmer, who once swam 90 miles non-stop. The Toronto Daily Star reported the following in 1918:

'A little six-year-old girl is the only survivor of the family of Bill Nye, the well-known Wellington baseball catcher. Nye's wife sickened with the flu two weeks ago and Nye nursed her until she died-Friday. She was buried Monday. Nye sickened himself on the day his wife died, and when she was buried he was critically ill. He developed pneumonia, and died early this morning at his home... A little girl of six years is the only survivor of the family.'

Killing the young was particularly tragic because it came on the heels of so many war deaths from the same age group. In this regard, the death of Wesley Lamb is particularly poignant:

'After ten days' illness from influenza and pneumonia Wesley Lamb died Monday, October 21. He had just recently returned from France, where he was a driver in the $127^{\text {th }}$ Battalion under Lieut.-Col. Clark. He enlisted before his sixteenth birthday, was wounded, gassed, and shell-shocked, and returned four days before his eighteenth birthday. He was buried Wednesday, October 23, in Mount Pleasant Cemetery.'

\subsection{Lessons}

Following a bioterrorism event, anger, fear, horror, and panic are very likely among both healthcare workers and the public. For example, people might experience distress related to personal or family illness, life disruption, grief related to loss of family, friends or co-workers, loss of routine support systems, and similar challenges.

Therefore, medical professionals should develop working relationships with mental health personnel, such as clergy, psychiatrists, psychologists, social workers, etc. as part of any disaster management plan.

Healthcare providers should receive education regarding bioterrorism, and should participate in disaster drills. A disaster plan should be developed to clearly explain risks, and to identify rapid evaluation and treatment.

\section{Conclusion}

In conclusion, medical and political leaders should honour the lessons of the 1918 Spanish influenza, which clearly demonstrate the vulnerabilities of government, healthcare, institutions, and the general population in the face of an infectious disease emergency.

A bioterrorism attack increases the risk, as naturally occurring agents can be manipulated 'to increase their ability to cause disease, make them resistant to current medicines, or to increase their ability to be spread into the environment'. These agents can also be extremely difficult to detect; moreover, they may not cause illness for several hours to several days, allowing some agents, such as the smallpox virus, to spread from person to person (APIC [8]). 


\section{References}

[1] Beveridge, W. 1977. Influenza: The Last Great Plague. An Unfinished Story of Discovery. Prodist: New York.

[2] Pettigrew, E. 1983. The Silent Enemy: Canada and the Deadly Flu of 1918. Western Producer Prairie Books: Saskatoon.

[3] Duncan, K. 2003. Hunting the 1918 Flu: One Scientist's Search for a Killer Virus. University of Toronto Press: Toronto.

[4] Crosby, A. 1976. Epidemic and Peace, 1918. Greenwood Press: Westport.

[5] Collier, R. 1974. The Plague of the Spanish Lady: The Influenza Pandemic of 1918-1919. Atheneum: New York.

[6] Schoch-Spana, M. 2000. Implications of pandemic influenza for bioterrorism response. Clinical Infectious Diseases 31:1409-13.

[7] Oxford, J., Sefton, A., Jackson, R. et al. 1999. Who's that lady? Nature Medicine 5: $1351-1352$.

[8] APIC Bioterrorism Task Force and CDC Hospital Infections Program Bioterrorism Working group. 1999. Bioterrorism Readiness Plan: a Template for Healthcare Facilities. http:/www.cdc.gov/ncidod/dhqp/ pdf/bt/13apr99APIC-CDCBioterrorism.PDF. 31/01/08.

[9] Duncan, K. 2006. Forewarned is forearmed. The 2006 Conference Board of Canada CSR Conference. Toronto, Canada, May 17, 2006. 